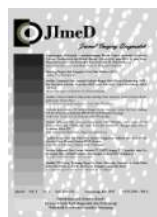

Jurnal Imejing Diagnostik (JImeD) 7 (2021) 22-27

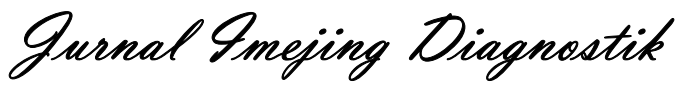

e-ISSN 2621-7457, p-ISSN 2356-301X

\title{
Standarisasi Indeks Eksposur Untuk Memenuhi Kriteria Anatomi Dan Aspek Teknis Pada Radiografi Thorax Pediatrik
}

\author{
Mukhammad Lutfan Nurrokhim ${ }^{1}$, Dwi Rochmayanti ${ }^{2}$, Ari Budiono ${ }^{3}$ \\ ${ }^{1}$ RS. Traumatologi Surabaya, Indonesia \\ ${ }^{2}$ Poltekkes Kemenkes Semarang, Indonesia \\ ${ }^{3}$ RSUD Dr. Lukmonohadi Kudus, Indonesia \\ Corresponding author: Mukhammad Lutfan Nurrokhim \\ e-mail: mukhammadlutfann@gmail.com
}

Received: July $14^{\text {th }}$, 2020; Revised: January $31^{\text {st }}, 2021$; Accepted: February $1^{\text {st }}, 2021$

\begin{abstract}
Background: Computed Radiography has an exposure index that used as an exposure indicator. But on radiographic examination, exposure index value sometimes ignored, and in the preliminary survey of pediatric chest examination resulting a large exposure index range. The aim of this study is to know the profile of exposure index value and the setting of the exposure factors, the assessment of anatomy criteria and technical aspect, and the right exposure factors such as $\mathrm{kV}$ and $\mathrm{mAs}$ on pediatric chest examination.

Methods: The type of this research is descriptive quantitative. The research was done by collecting data related to pediatric chest radiograph ( $\leq 2$ years) the value of exposure index was recorded, then the radiograph was assessed using questionnaires that filled by one respondent who is a radiologist. The data was analyzed by displaying the data of exposure index and anatomy criteria from questionnaires into the table form, and then conducted a descriptive analysis to be drawn conclusions.

Results: The results showed the profile of exposure index value and the setting of the exposure factor has a fairly large exposure index range of $1084-2175$, using $40 \mathrm{kV}$ and $10 \mathrm{mAs}$ and the collimation still often exceeds the object. Then for the assessment of the thorax anatomical criteria and the technical aspect overall was "Good Enough", and the right exposure factors, that is: at 6 and $7 \mathrm{~cm}$ chest thickness was using $60 \mathrm{kV}$ and $1,6 \mathrm{mAs}$; at $11 \mathrm{~cm}$ chest thickness was using $60 \mathrm{kV}$ and $2 \mathrm{mAs}$, FFD $100 \mathrm{~cm}$, and the setting of collimation as wide as object, the exposure index generated in the normal range that is 1251 $-1382$.

Conclusion: The right exposure factors on pediatric chest examination, that is: at 6 and $7 \mathrm{~cm}$ chest thickness was using $60 \mathrm{kV}$ and 1,6 mAs; at $11 \mathrm{~cm}$ chest thickness was using $60 \mathrm{kV}$ and $2 \mathrm{mAs}$, FFD 100 $\mathrm{cm}$, and the setting of collimation as wide as object.
\end{abstract}

Keywords: exposure index; pediatric chest radiography; thorax anatomical criteria

\section{PENDAHULUAN}

Pemeriksaan radiografi thorax merupakan prosedur radiografi yang paling sering dilakukan (Bontrager, 2005). Hal ini dimungkinkan karena dari pemeriksaan thorax dapat digunakan untuk melihat keadaan umum pasien, mendiagnosa penyakit di daerah paru, kebutuhan sebelum operasi dan lain-lain. Pemeriksaan radiografi thorax tidak hanya dilakukan pada orang dewasa, tetapi juga dilakukan pada pediatrik (anak-anak).

Dibandingkan orang dewasa seorang anak tubuhnya sedang dalam proses tumbuh kembang, sehingga menjadikannya lebih sensitif terhadap radiasi (Zhang, dkk cit. UNSCEAR 1988). Sehingga resiko anak pada umur 0-19 tahun untuk terkena kanker akibat paparan radiasi akan meningkat menjadi 3 kali lebih besar dibandingkan setelah umur 20 tahun (Zhang, dkk cit. ICRP 1991).

Pada saat dilakukannya prosedur pemeriksaan radiografi thorax pada anak, harus mengikuti prinsip ALARA (as low as reasonably achievable) sehingga perlu diperhatikan hal-hal yang meliputi dihasilkannya gambaran thorax dengan kualitas maksimal, dan dosis radiasi sekecil mungkin yang diterima oleh anak.

Untuk dapat menghasilkan kualitas radiograf yang baik pada film-screen radiografi konvensional perlu pengaturan faktor eksposi yang tepat seperti $\mathrm{kV}$ dan $\mathrm{mAs}$, sehingga tidak dihasilkan citra yang underexposed atau overexposed. Namun pada Computed Radiografi (CR) dan Digital Radiografi 
(DR), pemrosesan gambar dapat dikompensasi sampai $100 \%$ untuk underexposed dan $500 \%$ untuk overexposed, serta masih memberikan gambaran klinis yang selalu dapat diterima (Butler, dkk cit. Peters 2002). Sehingga sulit ditentukan secara visual apakah gambaran pada $\mathrm{CR}$ tersebut underexposed atau overexposed.

Gambaran digital pada CR memiliki rentang eksposur yang lebar, sehingga dapat mengurangi pengulangan foto karena faktor eksposi yang tidak tepat. Ketepatan faktor eksposi ditentukan dengan cara mengecek indeks eksposur, yang dapat diperoleh setelah gambaran digital diproses.

Indeks eksposur pada CR digunakan sebagai indikator atau nilai dosis radiasi yang diterima detektor dan ditampilkan pada citra (Butler dkk, 2010). Nilai indeks eksposur dipengaruhi oleh $\mathrm{mAs}, \mathrm{kV}$, total area detektor teradiasi dan objek yang dieksposi (Bontrager, 2005). Oleh Zhang dkk pada jurnalnya tahun 2012 disebutkan rentang nilai indeks eksposur pada manufaktur Kodak Carestream untuk pemeriksaan thorax pediatrik ( $\leq$ 2 tahun) adalah 1200-1390. Pada sistem Carestream, setiap peningkatan nilai indeks eksposur sebesar 300 menandakan terjadinya double exposure pada plate (Butler, dkk, 2010).

Pemeriksaan radiografi thoraks menjadi pemeriksaan radiologi yang paling banyak dilakukan di radiologi, khususnya pada anak yang baru lahir yaitu berada pada ruang PICU/NICU. Pada pemeriksaan thorax anak, pengaturan faktor eksposi sudah diperhatikan sesuai dengan faktor eksposi rutin. Namun radiografer cenderung hanya lebih memperhatikan kualitas citra yang dihasilkan saja dan kurang memperhatikan nilai indeks eksposur yang muncul di CR, sehingga radiografer tidak mengetahui apakah indeks eksposur dalam rentang normal atau tidak. Meskipun pada survey pendahuluan yang dilakukan oleh penulis pada pemeriksaan thorax pediatrik sebelumnya menghasilkan rentang indeks eksposur yang cukup besar yaitu 1084-2175. Dari hal tersebut, penulis ingin mengetahui profil nilai indeks eksposur dan pengaturan pesawat sinar-X, penilaian kriteria anatomi dan aspek teknis, serta faktor eksposi $(\mathrm{kV}$ dan $\mathrm{mAs}$ ) yang tepat pada thorax pediatrik.

\section{METODE}

Jenis penelitian yang digunakan penulis dalam penelitian ini adalah jenis penelitian kuantitatif deskriptif. Populasi pada penelitian ini adalah semua pasien pemeriksaan thorax pediatrik $(\leq 2$ tahun) proyeksi Antero-Posterior (AP) di Instalasi RSUD. Dr. Lukmonohadi Kudus. Sampel pada penelitian ini adalah pasien pemeriksaan thorax pediatrik ( $\leq 2$ tahun) proyeksi AP. Metode pengumpulan data yang digunakan dalam penelitian ini yaitu dokumentasi data indeks eksposur dan pengisian kuesioner mengenai penilaian kriteria anatomi. kemudian dilakukan analisis deskriptif untuk dapat ditarik kesimpulan.

\section{HASIL DAN PEMBAHASAN}

Profil nilai indeks eksposur dan pengaturan pesawat sinar-X yang meliputi faktor eksposi ( $\mathrm{V}$ dan mAs) dan kolimasi pada pemeriksaan radiografi thorax

Pada survey pendahuluan dapat diketahui bahwa rentang nilai indeks eksposur yang dihasilkan pada pemeriksaan radiografi thorax pediatrik adalah 1084 - 2175. Oleh Zhang dkk pada jurnalnya tahun 2012 disebutkan rentang nilai indeks eksposur pada manufaktur Kodak Carestream untuk pemeriksaan thorax pediatrik $(\leq$ 2 tahun) adalah 1200-1390, sehingga dapat dikatakan bahwa rentang nilai indeks eksposur yang dihasilkan memiliki rentang yang cukup besar. Kemudian untuk pengaturan faktor eksposi yang dilakukan pada pemeriksaan radiografi thorax pediatrik rutin di lapangan menggunakan 40 $\mathrm{kV}$ dan $10 \mathrm{mAs}$, yang dirasa pengaturan tersebut terlalu tinggi untuk pemeriksaan pasien pediatrik, sehingga dari pengamatan sebelumnya nilai indeks eksposur yang dihasilkan masih dalam rentang yang terlalu tinggi. Menurut European Guidelines On Quality Criteria For Diagnostic Radiographic Images In Paediatrics (European Commission, 1996) disebutkan pengaturan faktor eksposi untuk pasien pediatrik yaitu $60-65 \mathrm{kV}$ dan $1,6-2 \mathrm{mAs}$. Dan pada pengaturan luasan kolimasi untuk pemeriksaan radiografi thorax sering ditemukan bahwa diatur melebihi luasan objek yang diperiksa, yang mana hal ini juga mempengaruhi nilai indeks eksposur menjadi lebih besar. Ini juga sesuai dengan teori Rochmayanti, dkk (2017) yang menyebutkan bahwa faktor kolimasi memberikan pengaruh sebesar $49 \%$ terhadap indeks eksposur. Sehingga dari pemaparan di atas dapat diketahui bahwa penentuan faktor eksposi ( $\mathrm{kV}$ dan $\mathrm{mAs})$ yang sesuai serta pengaturan luasan kolimasi seluas objek dapat memberikan nilai indeks eksposur yang optimal dan diharapkan dapat mengurangi risiko akibat radiasi bagi pasien pediatrik.

Penilaian kriteria anatomi dan aspek teknis pada pemeriksaan radiografi thorax pediatrik

Hasil dari penelitian yang telah dilakukan didapatkan sampel sebanyak 22 pasien pemeriksaan radiografi thorax pediatrik (umur $\leq 2$ 
tahun) proyeksi AP. Kemudian dilakukan penilaian kriteria anatomi thorax dan aspek teknis menggunakan kuesioner. Hasil penilaian kriteria anatomi oleh responden secara keseluruhan kategori nilai total kriteria anatomi thorax pada 22 sampel tersebut adalah "Cukup Baik" dengan rentang nilai total berada antara $21-27$, yang mana dari hasil tersebut dapat dikatakan bahwa seluruh citra yang dihasilkan dapat memberikan informasi dan kriteria anatomi yang cukup baik sehingga sudah dapat menegakkan diagnosa dokter radiolog.

Distribusi frekuensi hasil penilaian terhadap kriteria anatomi thorax dari kuesioner yang telah diisi oleh responden akan ditampilkan satu per satu untuk setiap kriterianya dalam bentuk diagram batang.
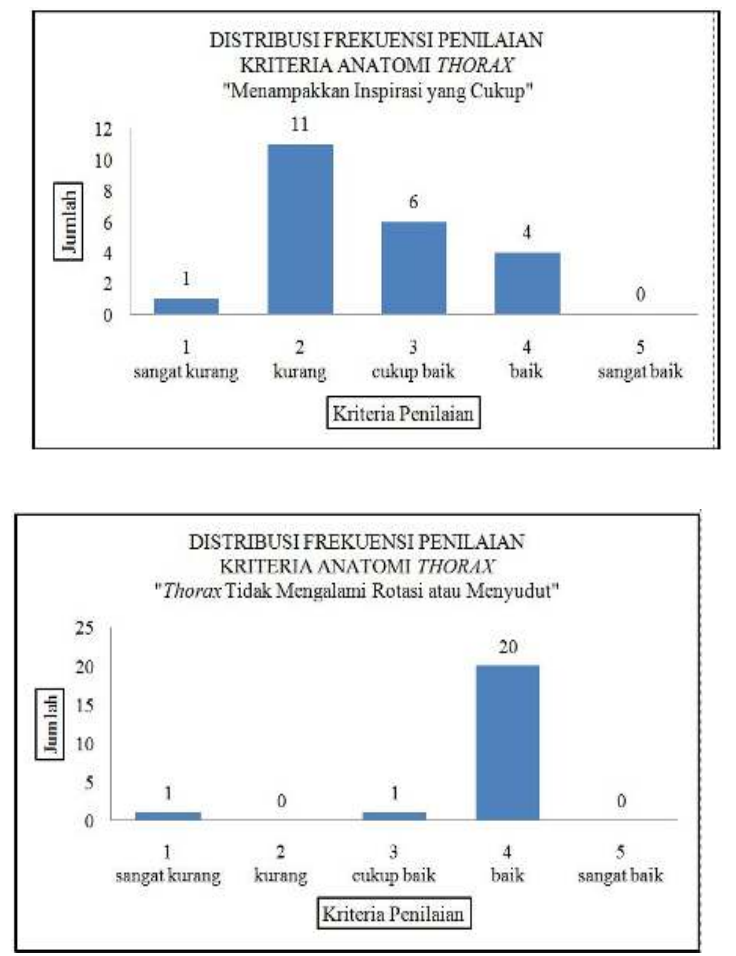

Gambar 2. Diagram distribusi frekuensi hasil penilaian terhadap kriteria anatomi thorax "thorax tidak mengalami rotasi atau menyudut"

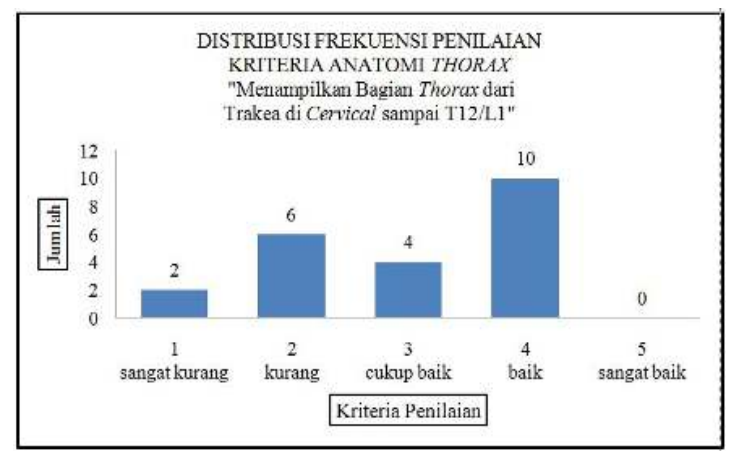

Gambar 3. Diagram distribusi frekuensi hasil penilaian terhadap kriteria anatomi thorax "menampilkan bagian thorax dari trakea di cervical sampai T12/L1"
Gambar 1. Diagram distribusi frekuensi hasil penilaian terhadap kriteria anatomi thorax "menampakkan inspirasi yang cukup"

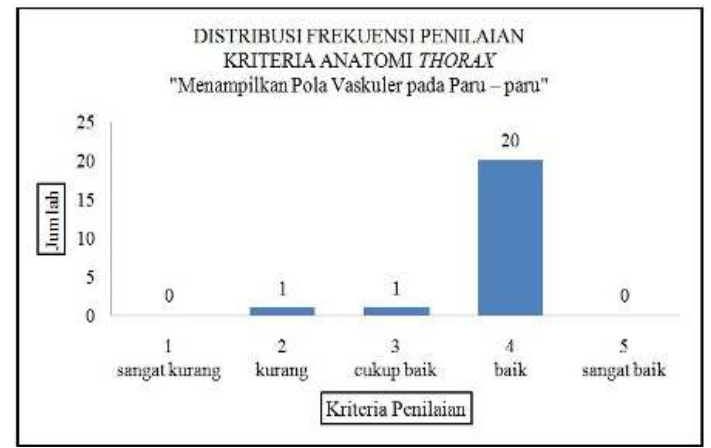

Gambar 4. Diagram distribusi frekuensi hasil penilaian terhadap kriteria anatomi thorax "menampilkan pola vaskuler pada paru-paru”

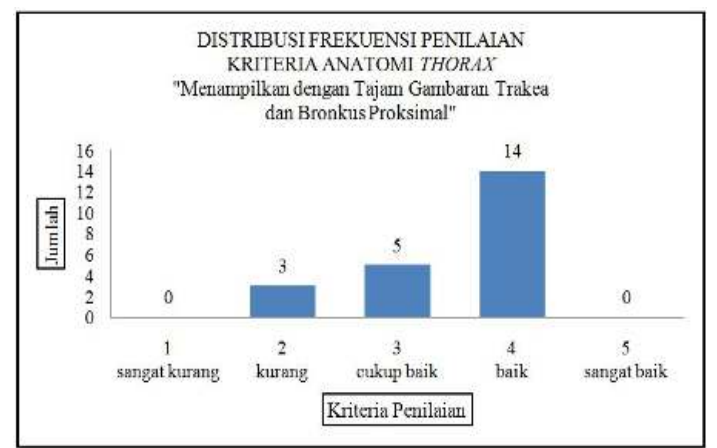

Gambar 5. Diagram distribusi frekuensi hasil penilaian terhadap kriteria anatomi thorax "menampilkan dengan tajam gambaran trakea dan bronkus proksimal”

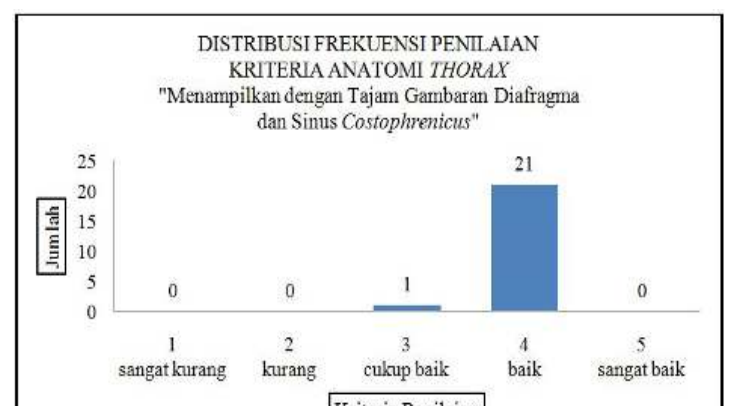

Gambar 6. Diagram distribusi frekuensi hasil penilaian terhadap kriteria anatomi thorax "menampilkan dengan tajam gambaran diafragma dan sinus costophrenicus"

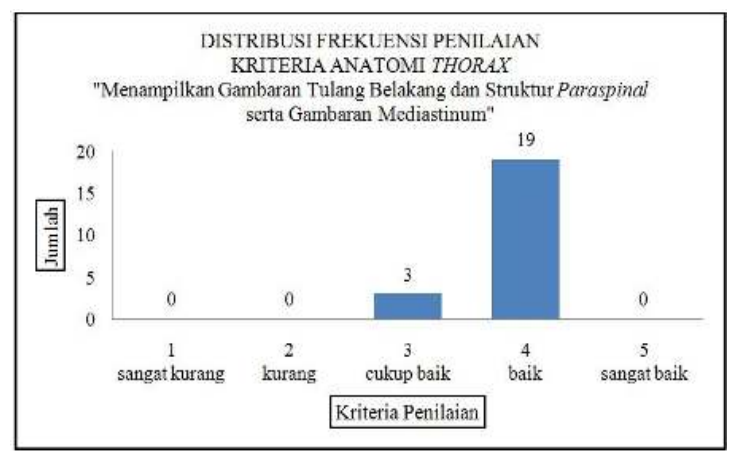

Gambar 7. Diagram distribusi frekuensi hasil penilaian terhadap kriteria anatomi thorax "menampilkan gambaran tulang belakang dengan struktur paraspinal serta gambaran 
Dari hasil distribusi frekuensi pada penilaian kriteria anatomi thorax yang ditampilkan oleh diagram di atas dapat diketahui bahwa hanya pada kriteria anatomi "menampakkan inspirasi yang cukup" saja yang memiliki frekuensi paling dominan pada angka penilaian 2 (kurang) (dapat dilihat di gambar 1), ini dikarenakan secara teknis pada praktiknya pasien pediatrik tidak dapat dilakukan eksposi pada saat inspirasi penuh, karena pasien tidak cukup kooperatif sehingga dilakukan eksposi pada saat inspirasi biasa.

Kemudian untuk kriteria anatomi thorax lainnya seperti, "thorax tidak mengalami rotasi atau menyudut" (dapat dilihat digambar 2), "menampilkan bagian thorax dari trakea di cervical sampai T12/L1" (dapat dilihat di gambar 3), "menampilkan pola vaskuler pada paru-paru" (dapat dilihat di gambar 4), "menampilkan dengan tajam gambaran trakea dan bronkus proksimal" (dapat dilihat di gambar 5), "menampilkan dengan tajam gambaran diafragma dan sinus costophrenicus" (dapat dilihat di gambar 6), dan "menampilkan gambaran tulang belakang dengan struktur paraspinal serta gambaran mediastinum" (dapat dilihat di gambar 7) memiliki frekuensi paling dominan pada angka penilaian 4 (baik), maka dari hasil tersebut dapat dikatakan bahwa secara kualitas citra dapat menampilkan anatomi dengan baik.

Sedangkan pada hasil penilaian aspek teknis oleh responden terdapat beberapa sampel yang tidak memenuhi salah satu aspek dari ketiga aspek teknis. Terdapat 2 pasien dari 22 sampel $(9,1 \%)$ tidak memenuhi aspek kesimetrisan, karena pada pasien pediatrik lebih cenderung tidak kooperatif sehingga objek lebih rentan untuk bergerak, dan pada praktiknya di lapangan tidak menggunakan alat bantu fiksasi untuk pasien. Hal ini dapat berdampak pada citra yang dihasilkan, yaitu dapat menghasilkan blurring atau gambar tidak fokus pada citra yang disebabkan adanya pergerakan saat dieksposi dan objek pada citra tidak terlihat simetris karena objek berotasi atau bergeser saat eksposi. Maka dari itu pada setiap pemeriksaan thorax pediatrik khususnya pada pasien yang kurang kooperatif

diperlukan fiksasi yang baik, seperti menurut Whitley, dkk (2005) pada bayi yang terdapat dalam inkubator dapat dilakukan fiksasi oleh keluarga atau pendamping pasien dengan memasukkan kedua tangan melewati dua lubang yang terdapat pada sisi inkubator kemudian memegangi kedua tangan pasien di samping kepala dan kedua kakinya juga dipegangi pada bagian lutut. Kemudian terdapat 5 pasien dari 22 sampel $(22,7 \%)$ yang tidak memenuhi aspek pengaturan luas lapangan kolimasi yang dalam hal ini kolimasi melebihi objek, dan memberikan nilai indeks eksposur di atas rentang normal.

Hal ini menunjukkan bahwa pengaturan kolimasi yang melebihi objek masih menjadi permasalahan yang terjadi. Menurut Butler pada jurnalnya tahun 2010 disebutkan bahwa pada sistem Carestream, setiap peningkatan nilai indeks eksposur sebesar 300 menandakan terjadinya double exposure pada plate, sehingga dari pernyataan tersebut kemungkinan nilai dosis radiasi yang diterima oleh pasien pediatrik akan lebih besar pada sampel yang mendapat nilai indeks eksposur di atas rentang normal. Ini dapat menimbulkan dampak negatif bagi pasien pediatrik. Zhang, dkk (2012) menyebutkan bahwa dibandingkan dengan orang dewasa seorang anak lebih sensitif terhadap radiasi karena sedang dalam proses tumbuh kembang, sehingga risiko anak pada umur 0 - 19 tahun untuk terkena kanker akibat paparan radiasi akan meningkat menjadi 3 kali lebih besar dibandingkan setelah umur 20 tahun.

Maka dari itu dalam pengaturan luasan kolimasi harus menjadi perhatian khusus bagi para radiografer untuk kedepannya agar diatur seluas objek dengan harapan dapat mengurangi risiko akibat radiasi bagi pasien pediatrik.

Faktor eksposi (kV dan mAs) yang tepat pada pemeriksaan radiografi thorax pediatrik sehingga memberikan nilai indeks eksposur yang sesuai dan kriteria anatomi serta aspek teknis yang baik

Pemeriksaan radiografi thorax pediatrik pada penelitian ini menggunakan faktor eksposi yang diatur dengan menyesuaikan ketebalan thorax pasien yang akan diperiksa, dan FFD diatur tetap yaitu $100 \mathrm{~cm}$. 
Tabel 1. Faktor Eksposi dan Hasil Nilai Indeks Eksposur

\begin{tabular}{ccccccccc}
\hline $\begin{array}{c}\text { No } \\
\text { Pasien }\end{array}$ & Umur & $\begin{array}{c}\text { Tebal Thorax } \\
(\mathrm{cm})\end{array}$ & $\mathrm{kVp}$ & $\mathrm{mAs}$ & $\mathrm{FFD}(\mathrm{cm})$ & $\mathrm{IE}$ & Keterangan IE & Kolimasi \\
\hline 1 & 1 tahun & 11 & 60 & 2 & 100 & 1887 & Di atas normal & Seluas objek \\
2 & 1 tahun & 11 & 60 & 2 & 100 & 1340 & Normal & Seluas objek \\
3 & 1 hari & 7 & 60 & 1,6 & 100 & 1551 & Di atas normal & Seluas objek \\
4 & 1 hari & 7 & 60 & 1,6 & 100 & 1390 & Normal & Seluas objek \\
5 & 7 bulan & 9 & 60 & 2 & 100 & 1738 & Di atas normal & Seluas objek \\
6 & 1 hari & 6 & 60 & 2 & 100 & 1989 & Di atas normal & Melebihi objek \\
7 & 1 thn 5 bln & 13 & 60 & 2 & 100 & 1621 & Di atas normal & Melebihi objek \\
8 & 1 hari & 6 & 60 & 1,6 & 100 & 1102 & Di bawah normal & Seluas objek \\
9 & 1 tahun & 14 & 60 & 2 & 100 & 1786 & Di atas normal & Seluas objek \\
10 & 1 hari & 5 & 58 & 1,6 & 100 & 1087 & Di bawah normal & Seluas objek \\
11 & 1 hari & 6 & 60 & 1,6 & 100 & 1251 & Normal & Seluas objek \\
12 & 7 bulan & 8 & 60 & 2 & 100 & 1648 & Di atas normal & Melebihi objek \\
13 & 1 hari & 6 & 60 & 1,6 & 100 & 1306 & Normal & Seluas objek \\
14 & 1 hari & 6 & 60 & 2 & 100 & 1879 & Di atas normal & Melebihi objek \\
15 & 1 hari & 6 & 60 & 1,6 & 100 & 1270 & Normal & Seluas objek \\
16 & 1 hari & 5 & 60 & 1,6 & 100 & 1327 & Normal & Seluas objek \\
17 & 2 bulan & 8 & 60 & 1,6 & 100 & 1670 & Di atas normal & Seluas objek \\
18 & 28 hari & 7 & 60 & 1,6 & 100 & 1382 & Normal & Seluas objek \\
19 & 1 tahun & 13 & 60 & 2 & 100 & 1718 & Di atas normal & Melebihi objek \\
20 & 19 hari & 6 & 60 & 1,6 & 100 & 1334 & Normal & Seluas objek \\
21 & 4 hari & 7 & 60 & 1,6 & 100 & 1295 & Normal & Seluas objek \\
22 & 1 hari & 5 & 57 & 1,57 & 100 & 1742 & Di atas normal & Seluas objek \\
\hline
\end{tabular}

Berdasarkan tabel 1, dari seluruh pasien yang dijadikan sampel dengan jumlah 22 pasien, nilai indeks eksposur yang dihasilkan memiliki rentang 1087 - 1989, menurut Zhang dkk pada jurnalnya tahun 2012 disebutkan rentang nilai indeks eksposur yang normal pada manufaktur Kodak Carestream untuk pemeriksaan thorax pediatrik $(\leq$ 2 tahun) adalah 1200 - 1390, sehingga terdapat 9 pasien yang menghasilkan nilai indeks eksposur dalam rentang normal.

Namun hanya 7 pasien yang memenuhi kriteria teknis, yaitu pasien nomor 2, 11, 13, 15, 18, 19, 20, dan 21 (tabel 2). Hal ini dikarenakan pada pasien nomor 4 dan 16 pada penilaian aspek teknis oleh responden terdapat satu aspek yang tidak terpenuhi yaitu objek tidak terlihat simetris.

Dari tabel 2 dapat dilihat bahwa terdapat 7 pasien yang memenuhi kriteria teknis. Terdapat 3 ukuran ketebalan thorax pasien yaitu 6, 7, dan 11 $\mathrm{cm}$. Pada pasien dengan ketebalan thorax 6 dan 7 $\mathrm{cm}$ menggunakan faktor eksposi $60 \mathrm{kV}$ dan 1,6 mAs yang menghasilkan nilai indeks eksposur antara 1251 - 1382, sedangkan pada pasien dengan ketebalan $11 \mathrm{~cm}$ menggunakan faktor eksposi 60 $\mathrm{kV}$ dan $2 \mathrm{mAs}$ yang menghasilkan nilai indeks eksposur 1340, dengan FFD pada kedua pengaturan faktor eksposi berjarak sama yaitu $100 \mathrm{~cm}$. Dari dua macam pengaturan faktor eksposi ini menghasilkan nilai indeks eksposur dalam rentang yang normal dan berdasarkan penilaian kriteria anatomi thorax oleh responden, ketujuh data pasien yang memenuhi kriteria teknis memiliki kategori nilai total "Cukup Baik" dengan nilai antara 21 27.

Karena keterbatasan waktu dari penelitian ini, hanya didapatkan dua kombinasi faktor eksposi yang disesuaikan dengan ketebalan thorax pasien sehingga mendapatkan nilai indeks eksposur dalam rentang yang normal. Untuk selanjutnya radiografer dapat mengacu dari hasil penelitian ini, sehingga didapatkan kombinasi faktor eksposi lain yang disesuaikan dengan ketebalan thorax pasien dari pengamatan yang dilakukan disetiap pemeriksaan di masa yang akan datang dan diharapkan dapat memberikan indeks eksposur yang optimal.

Selain mAs, $\mathrm{kV}$, dan ketebalan objek, menurut Bontrager (2005) nilai indeks eksposur juga dipengaruhi oleh total area detektor teradiasi atau luas lapangan kolimasi. Pada beberapa pemeriksaan thorax di penelitian ini ditemukan beberapa pasien yang pada pengaturan kolimasinya melebihi objek, sehingga menghasilkan nilai indeks eksposur di atas rentang normal. Namun pada 7 pasien yang memenuhi kriteria teknis di penelitian ini, pengaturan luasan kolimasinya diatur seluas objek sehingga menghasilkan nilai indeks eksposur dalam rentang normal. 
Tabel 2. Data Pasien yang Memenuhi Kriteria Teknis

\begin{tabular}{cccccccc}
\hline $\begin{array}{c}\text { No } \\
\text { Pasien }\end{array}$ & $\begin{array}{c}\text { Teba } \\
(\mathrm{cm})\end{array}$ & $\mathrm{kV}$ & $\mathrm{mAs}$ & IE & Kolimasi & $\begin{array}{c}\text { Kesimet } \\
\text { risan }\end{array}$ & Positioning \\
\hline 2 & 11 & 60 & 2 & 1340 & $\begin{array}{c}\text { Seluas } \\
\text { objek }\end{array}$ & Simetris & Tepat \\
11 & 6 & 60 & 1,6 & 1251 & $\begin{array}{c}\text { Seluas } \\
\text { objek }\end{array}$ & Simetris & Tepat \\
13 & 6 & 60 & 1,6 & 1306 & $\begin{array}{c}\text { Seluas } \\
\text { objek } \\
\text { Seluas } \\
\text { objek }\end{array}$ & Simetris & Tepat \\
15 & 6 & 60 & 1,6 & 1270 & Tepat \\
18 & 7 & 60 & 1,6 & 1382 & $\begin{array}{c}\text { Seluas } \\
\text { objek } \\
\text { Seluas } \\
\text { objek }\end{array}$ & Simetris & Tepat \\
20 & 6 & 60 & 1,6 & 1334 & Tepat \\
21 & 7 & 60 & 1,6 & 1295 & $\begin{array}{c}\text { Seluas } \\
\text { objek }\end{array}$ & Simetris & Tepat \\
\hline
\end{tabular}

\section{KESIMPULAN}

Profil nilai indeks eksposur dan pengaturan pesawat sinar-X pada pemeriksaan thorax pediatrik rutin di lapangan ditemukan beberapa kekurangan, seperti pengaturan faktor eksposi $(\mathrm{kV}$ dan $\mathrm{mAs})$ rutin $40 \mathrm{kV}$ dan $10 \mathrm{mAs}$ dan pengaturan luas lapangan kolimasi yang sering melebihi objek memberikan nilai indeks eksposur yang masih dalam rentang terlalu tinggi yakni $1084-2175$.

Penilaian kriteria anatomi dan aspek teknis pada pemeriksaan radiografi thorax pediatrik secara keseluruhan kategori nilai total kriteria anatomi thorax pada 22 sampel tersebut adalah "Cukup Baik" dengan rentang nilai total berada antara $21-27$.

Faktor eksposi ( $\mathrm{kV}$ dan $\mathrm{mAs}$ ) yang tepat pada pemeriksaan radiografi thorax pediatrik, yaitu: pada ketebalan thorax 6 dan $7 \mathrm{~cm}$ menggunakan faktor eksposi $60 \mathrm{kV}$ dan 1,6 mAs, FFD $100 \mathrm{~cm}$, dan kolimasi diatur seluas objek; pada ketebalan thorax $11 \mathrm{~cm}$ menggunakan faktor eksposi $60 \mathrm{kV}$ dan $2 \mathrm{mAs}$, FFD $100 \mathrm{~cm}$, dan kolimasi diatur seluas objek. Dari pengaturan tersebut dihasilkan citra dalam kategori nilai "Cukup Baik", dan indeks eksposur yang dihasilkan yaitu 1251 - 1382 masuk dalam rentang yang dipersyaratkan.

\section{DAFTAR PUSTAKA}

Bontrager, K. L., dan John P. Lampignano. 2005. Radiographic Positioning and Related Anatomy, $\sigma^{\text {th }}$ Edition. United State of America: Elsevier Mosby.

Butler, M. L. dkk. Are Exposure Index Values Consistent in Clinical Practice? A MultiManufacturer Investigation. Radiation Protection Dosimetry 2010; Vol. 139: No. 1-3, Hal. 371-374.
Carlton, R. R. dan Arlene McKenna Adler. 2012. Principles of Radiographic Imaging: An Art and A Science. Cengage Learning.

Cohen, M. D., dkk. Quality Assurance: Using the Exposure Index and The Deviation Index to Monitor Radiation Exposure for Portable Chest Radiographs in Neonates. Pediatr Radiol 2010.

European Commission. 1996. European Guidelines on Quality Criteria for Diagnostic Radiographic Images in Paediatrics. Luxembourg: Office for Official Publications of the European Communities.

Kirks, Donald R. dan Nathan Thorne Griscom. 1998. Practical Pediatric Imaging: Diagnostic Radiology of Infants and Children. Lippincott Williams \& Wilkins.

Lavin, Lisa M., 2006. Radiography in Veterinary Technology Fourth Edition. Missouri: Elsevier Health Sciences.

Oliveira, A., C., dkk. Visual Grading Analysis of image quality in Pediatric abdominal images acquired by Direct Digital Radiography and Computer Radiography Systems. European Society of Radiology 2013; C-2098.

Rochmayanti, Dwi, dkk. Faktor Determinan Kolimasi, Ukuran Imaging Plate, dan Delay Time Processing terhadap Exposure Index. Jurnal Riset Kesehatan 2017; 6(2):1-6.

Seibert, J. Anthony dan Richard L. Mortin. The Standardized Exposure Index for Digital Radiography: an Opportunity for Optimzing of Radiation Dose to the Pediatric Population. Pediatr Radiol 2011; 41:573-581.

Whitley, A. Stewart, Charles Sloane, Graham Hoadley, Adrian D. Moore, dan Chrissie W. Alsop. 2005. Clark's Positioning in Radiography. London: Hodder Arnold.

Zhang, Menglong, dkk. A Method to Derive Appropriate Exposure Parameters from Target Exposure Index and Patient Thickness in Pediatric Digital Radiography. Pediatr Radiol 2013; 43:568574.

Z\&Z Medical Inc., 2017, Carestream CR Cassettes and Plates, zzmedical.com, diunduh 18 Januari 2018 pada pukul 16.42 WIB. 